$24 / 2 / 25$

Informal Report

\section{Specifications and Test Procedures for Airline-Type Supplied-Air Suits}

by

William H. Revoir, Project Manager

John A. Pritchard

Charles P. Richards

Thomas O. Davis

Lloyd D. Wheat

UC-41

Reporting Date: April 1975

Issued: May 1975 
In the interest of prompt distribution, this report was not edited by the Technical Information staff.

Work supported by the Division of Operational Safety, US Energy Research and Development Administration.

Printed in the United Slates of America. Available from Nutional Tochnicul Intormation Service

US Department of Commerce

5285 Port Royal Road

Springfield, VA 22IS!

Price: Prinlea Copy \$4.00 Microfiche $\$ 2.25$

Thin report was pregured ws un accuunt of work spongored

bo th. ' nited slatrs covernmrnl. Neither the Enites Stutes

nor the l'nited stutey Einerks Researih and Development Ad.

Iratorn. aubuntructorn, or their ereployes. mukes any

uarrant, express or implied, or asoumess any legal liabilits or

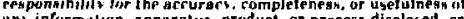

une informallinn, apouratuo, product, or proeses diaclosed, of

richenc. 
1. General Provisions . . . . . . . . . . . . . . . 2

1.1. Purpose .. . . . . . . . . . . . . . . . 2

1.2. Airline-Type Supplied-Air Suits For Evaluation of

Performance .................. . 2

1.3. Airline-Type Supplied-Air Suit Description . . . . 2

2. Procedures and Requirements for Having Airline-Type Supplied-Air Suit Evaluated For Performance . . . . . . 2

3. Conduct of Examinations and Tests, Assistance, Observers, and Confidentialities . . . . . . . . . . . . . . . 4

3.1. Conduct of Examinations and Tests . . . . . . . . 4

3.2. Assistance . . . . . . . . . . . . . . 4

3.3. Observers . . . . . . . . . . . . . . . 4

3.4. Confidentialities . . . . . . . . . . . . 4

4. General Construction Requirements . . . . . . . . . . . 4

5. General Operating Requirements . . . . . . . . . . . . 5

6. Examination and Test Procedures, Performance Criteria . 5

6.1. General Examination and Tast Procedures . . . . 5

6.2. Performance Criteria... . . . . . . . . . 5

6.3. Reports . . . . . . . . . . . . . . . 5

6.4. Airline-Type Supplied-Air suit for Use in Tests to Determine Performance Characteristics . . . . . 6

6.5. Human Test Subjects . . . . . . . . . . . . 6

6.6. Examination . . . . . . . . . . . . . 7

6.7. Donning and Wearing of Airline-Type Supplied-Air

Suit by Human Test subject... . . . . . . . . 7

6.8. Determination of Accuracy of Air-Flon Indicator * 7

6.9. Respiratory Protection . . . . . . . . . . . . 8

6.10. Crush Resistance of Supply Air Hose . . . . . . Il

6.11. Nonkinkability of Supply Air Hose . . . . . . . 11

6.12. Strength of Supply Air Hose and Couplings . . . . 12

6.13. Strength of Connection of Supply Air Hose to

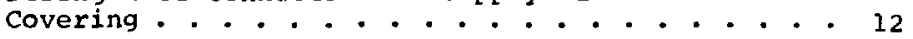

6.14. Noise ..................... . 14

This report was prepared as an accowat of work

the Unted the United States Cowmenent. Nother the United State nor the United Stutes Bnory Rewerch and Devolopmen Mdminitintion, nor any of thet employee, nor any of their contractore, abcontractors, or their employes, ciakes merranty, expres or impliad or emence inbitsy or recponciblity tor the accuracy, complestents or unelulne of any informetion, anpantun, product or prosent uppintus, produet or proces diccloned, or represeats that its we would not 
by

William H. Revoir, Project Manager John A. Pritchard Thomas O. Davis Charles P. Richards Lloyd D. Wheat

\begin{abstract}
Procejures and requirements have been established to permit airline-type supplied-air suits needed by contractors of the Energy Research and Development Administration to be tested ior performance by the Respirator Research and Development Section. Industrial Hygiene Group, of the Los Alamos Scientific Laboratory, and to have the adequacy of the performance of these devices evaluated by the Los Alamos Scientific Laboratory Respirator Advisory Committee. Test equipment, test methods, and performance criteria for airline-type supplied-air suits are prescribed.
\end{abstract}


1.

\subsection{Purpose}

The purpose of this document is: (a) to establish procedures and to prescribe requirements which must be met in having airline-type supplied-air suits needed by contractors of the Eusiyy Research and Development Administration (ERDA) for protection of workers against inhalation of harmful atmospheres evaluated for performance by the Respirator Research and Development Section (RRDS), Industrial Hygiene Group (IHG), of the Los Alamos Scientific Laboratory (LASI; and to have the adequacy of the performance of the devices reviewed by the LASL Respirator Advisory Committee; (b) to prescribe test equipment and test methods for evaluating the performance of airline-type suppliedair suits by the LASL RRDS; and (c) to specify minimum performance requirements for protection of workers against inhalation of harmful atmospheres.

\subsection{Airline-Type Supplied-Air Suits for Evaluation of Performance}

Any airline-type supplied-air suit, which is needed by an ERDA contractor for protection of workers against inhalation against harmful atmospheres and which is not eligible for test, approval, and certification by the National Institute for Occupational Safety and Health (NIOSH), Department of Health, Education, and Welfare (DHEW), and by the Mining Enforcement and Safety Administration (MESA), Department of Interior (DI), under the provisions of Title 30, Code of Federal Regulations, Part 11 ( $30 \mathrm{CFR}$ 11) is eligible for testing for performance by the LASL RRDS and for a review of the adequacy of its performance by the LASL Resfirator Advisory Committee.

\subsection{Airline-Type Supplied-Air Suit}

\section{Description}

An airline-type supplied-air suit is a respirator which contains a protective covering for the entire body including the head, torso, arms, and legs. The covering may consist of a single-piece garment or may be made up of two or more garment items that are designed to complement each other to protect the wearer. Compressed respirable air is supplied to the covering througi a supply air hose that is cuanected to a source of this air such as a compressor or a tank. The air may be supplied only to the head portion of the covering or to the head portion plus other parts of the covering. The airline-type supplied-air suit consists of the protective coverilug for the body of the wearer, the supply air hose, and other attachments, accessories, and auxiliary items such as a breathing tube, coupling, air flow control valve, air flow meter, air pressure gage, comunications equipment. gloves, boots, shoe coverings, etc. The head portion of the suit's covering may consist of a helmet-type or hood-type unit, or it may consist of a combination of a facepiece and helmet-type or hood-type unit.

2. PROCEDURES AND REQUIREMENTS FOR HAVINC; AIRLINE-TYPE SUPPLIED-AIR SUIT EVALUATED FOR PERFORMANCE

2.1. AnY ERDA contractor, who des: ies to use or who has in use an airline-type supplied-air suit for protection of workers against inhalation of harmful atmospheres which is not eligible for test, approval, and certification by NIOSH and MESA under the provisions of $30 \mathrm{CFR} 11$ and for which there is a specific need for the device, may submit a request to the appropriate ERDA Field oifice for an evaluation of the performance of the device and for a review of the adequacy of the performance of the device. The request shall include an expianation of the ineligibility of the device for test, approval, and certification by NIOSH and I:ESA und $r$ the provisions of $30 \mathrm{CFR} 11$. Also, the request shall include a statement of the need of the clevice. In addition, the request shall include a statement on whether or not the device is reusable, and if it or a portion of $i z$ is laundered,

2.2. The ERDA Field of $f$ ice shall forward a copy of the request to the ERDA Division of operational Safety, Health Protection Branch. 
2.3. The ERDA Division of Operational Safety, Health Protection Branch, shall review the request and decide whether or not the perfurmance of the airline-type suppliedair suit shall be evaluated and reviewed. If it is decided that the performance of the device shall be evaluated and reviewed, the ERDA Division of Operational Safety, Health Protection Branch, shall forward a copy of the request to the section Leader of the LASL RRDS along with a directive that the LASL RRDS test and evaluate the performance of the device. The ERDA Division of Operational Safety. Health Protection Branch, shall notify the ERDA Field office of its decision and shall instruct the ERDA Field office to notify the ERDA contractor of the decision.

2.4. If the decision has been made that the performance of the airline-type suppliedair suit shall be evaluated and reviewed, the ERDA Division of Operational Safety, Health Protection Branch, shall notify the ERDA Field offise to instruct the ERDA contractor to submit the device including the supply air hose and including all attachments, accessories, and auxiliary items (such as couplings, air-flow control valve, air-flow meter, air-pressure regulator, airpressure gage, communications equipment, gloves, boots, shoe coverings, etc.) and to submit the instructions for donning, operating, maintaining, and storing the device to the Section Leader of the LASL RRDS. If the device or a portion of the device is reusable and is laundered, the ERDA Division of Operational Safety. Health Protection Branch, shall notify the ERDA Field ofice to instruct the ERDA contractor to submit a laundered device along with a description of the laundering procedures and conditions and along with a notification of the number of times that the device has been laundered to the Section Leader of the LASL RRDS.

2.5. The LASL RRDS, upon receipt of the directive to test and evaluate the performance of the airline-type supplied-air suit and upon receipt of the device and all other items submitted, shall perform the necessary tests and shall compare the test results with performance criteria.

2.6. The LASL RRDS shall formulate conclusions and recommendations relative to the adequacy of the performance of the airlinetype supplied-air suit, shall write a report containing test data, conclusions, and recommendations, and the section Leader of the LASL RRDS shall forward copies of the report to the Chairman, Secretary, and members of the LASL Respirator Advisory Committee, and to the ERDA Division of operational Safety, Health protection Branch.

2.7. The LASL Respirator Advisory Committee shall study the report, review and evaluate the test results given in the report, and shall formulate its own conclusions and recommendations relative to the adequacy of the perfo:mance of the airline-type suppliedair suit. The Chairman of the LASL Respirator Advisoiy Comittee shall send a report containing he conclusions and recommendations to the Section Leader of the Los Alamos RRDS and a copy of the report tc the ERDA Eivision pf Operational Safety, Health Protection Branich.

2.8. The LASL RRDS shall consider the conclusions and recommendations connerning the adecuacy of the performance of the airlinetype supplied-air suit submitted by the LASL Respirator Advisory Committee and then formulate its own conclusions and recommendatic:us. The section Leader of the IASL RRDS shall forward a report containing the conclusions and recommendations concerning the adequacy of the performance of the device to the ERDA Division of Operational safety and shall send copies of the report to the Chairman, Secretary, and members of the LASL Respirator Advisory Comnit tee. 2.9. The ERDA Division of Operational Safety, Health Protection Branch, shall consider the conclusions and recommendations concerning the adequacy of the performance of the airline-type supplied-air suit submitted by the LASI. RRDS and shall formulate its own conclusions and recommendations. The ERDA 
Division of operational Safety, Health protection Branch, shall forward a report contairing its conclusions and recommendations pertaining to the adequacy of the performance of the device to the ERDA field office and shall instruct the ERDA Field office to notify the FRDA contractor of these conclusions and recommendations. The ERDA Division of Operational safety. Health protection Branch, shall send a copy of the report to the Section Leader of the LASL RRDS. 2.10. Thn ERDA Fielo office shall inform the ERDA contractor of the conclusions and recommendations concerning the adequacy of the performance of the airline-type supplied-dir suit made by the BroA Division of Operational Safery, lloalth Protection Branch.

2.11. The LASL RRDS shall ship the airlinetype supplied-air suit, attachrstts, accessories, and auxiliary items to the ERDA contractor after a report containing its conclusions and recomendations concerning tine adequacy of the performance of the device has been sant to the ERDA Division of operating Safety, Health protection Branch. 2.12. IE an airline-type supplied-air suit, which has been ovaluated for performance. is modified in construction or its operating conditions are changed, the ERDA contractor should resubmit the device for re-evaluation of its performance in accordance with procedures and requirements previously listed.

3. CONDUCT OF EXMMINRTIONS AND TESTS, ASSISTANCE, OBSERVERS, AND CONFIDENTIALITIES

3.1. Conduct of Examinations and Tests

3.1.1. A11 examinations and tests of the airline-type supplied-air suit subnitted by an ERDA contractor shall be under the sole direction and control of the LASL RRDS.

3.2. Assistance

3.2.1. The LASL RRDS may, as a condition of evaluating the performance of an airline-type supplied-air suit, require the assistance of the ERDA contractor who submitted the device or agents of the ER?A contractor during the examination or testing of the device.

\subsection{Observers}

3.3.1. Only personnel of the LASL RRDS, persons assisting the LASL RROS pursuant to 3.2.1, personisel of ERDA, nembers of the LisL Respirator Acvisory Committec. anci such other persons as are iequested by the LASL RRDS or ERDA, shall be present during any examinotion and test of the airline-type supplicst-air suit submitted by an ERDA contractor.

\subsection{Confidentialities}

3.4.1. The LASL RRDS shall hold as conficiential any cquipment, material, and other items provided by an ERDA contractor who susmits an airline-type supplied.air suit for evaluation of its performance, and shall supply information concerning thr: device only to the ERDA Division of Operational safety. llealth Protection Branch. and to the Chairman, Secretary, and members of the IAS! Respirator hevisory committee, excope as required by statuta or regulintion.

3.4.2. The LASL RRDS shall hold as confidential and sinall not disclose any patentable features of an airline-tyac supplicd-air suit submitted by an ERDA contractor for evaluation of ita performance. excopt an required by statute or requlation.

3.4.3. The LASL Rins shall hold as confidential and shail not disclose any test data, conclusions, and recommendations con cerning the performance of an airline-type supplied-air suit submitted by an ERDA contractor, except to the ERDA Division of Operational Safety, Health Protection Branch, to the chairman, secretary, and members of the LASL Respirator Advisory Conmittee, tc the ERos contractor on his written request, and except. as required by statute or rejulation.

\section{GENERAL CONSTRUCTION REQUIREMENTS}

4.1. An airline-type supplied-air suit submicted by an ERDA contractor for an evaluation of its performance shall not be accepted by the LASL RRDS for examination and 
testing unless the device has been designed on sound engineering and scientific principles, constructed of suitable materials, and shows evidence of good workmanship.

4.2. Components of an airline-type suppliedair suit, which come into contact with the wearer's skin, shall be composed of materials wich do not irritate the skin.

4.3. Components of an airline-type supplied-air suit, which must be disassembled or replaced during or after use of the device, shall be composed of matrials and constructed so that they are not damaged by normal handling.

4.4. Reusable components of an airline-type suppliediair respirator, which cone into contact with the wearer's skin or which must be cleaned after use, shall be composed of materials and constructed so that they will withstand repeated washing and sanitizing as prescribed by the instructions of tine ERDA contractor or the manufacturer of the device.

4.5 The airline-type supplied-air suit shall use an air-flow meter for measurement of the rate of flow of respirable air to the covering of the suit or shall use a pressure gage for indirect measurement of the rate cf flow of respirable air to thr. covering of the suit.

\section{GENERAL OPERATING REQUIREMENTS}

5.1. An airline-type supplied-air suit submitted by an ERDA contractor for an evaluation of its performance shali not be accepted by the LASL RRDS for examination and testing ur:less the device has been designed tc be operated with a minimum flow of air to the covering of the device which shall not be iess than $2.83 \times 10^{-3} \mathrm{~m}^{3} / \mathrm{s}(6.0 \mathrm{cfm})$.

3.2. An airline-type supplied-air suit submitted by an ERDA contractor for evaluation of its performance shall not be accepted by the LASL RRDS for examination and testing unless written instructions covering donsing operation, maintenance, and storage of the devj.ce are available.
6. EXAMINATZON AND TEST PROCEDURES, PERFORMANCE CRITERIA

6.1. General Examination and Test Procedures

6.1.1. Each airline-type suppliedair suit submitted by an ERDA contractor for evaluation of its performance shall be examined and tested by the LASI. RRDS in accordance with procedures set forth in Section 6 of this document.

6.1.2. In addition to the examination and test procedures set forth in Section 6 of this document, the LASL RRDS reserves the right to conduct any addjtional examinations and tests it deems necessary to determine the quality, construction, and performance of an airline-type supplied-air suit submitted by an ERDA contractor.

6.2. Performance Criteria

6.2.2. The performance criteria which an airline-type supplied-air suit submitted by an ERDA contractor must meet in order to be considered to provide adequate protection to workers against inhalation of harmful atmospheres are set forth in section 6 of this document.

6.2.3. The performance eriteria for an airline-type suit submitted by an ERDA contractor are those established by the LASI RRDS and agreed to by a consensus of the LASL Respirator Advisory Committee.

\subsection{Reports}

6.3.1. Upon completion of the examination and testing of the airline-type supplied-air suit submitted by an ERDA contractor, the 24SL RRDS shall formulate conclusions and recommendations concerning the adequacy of the performance of the device, and shall write a report containing the results of the examination and testing, observations made by examiners and test operators, comments made by human test subjects, conclusions, and recommendations. Copies of the report shall be forwarded by the section Leader of the IASL BRDS to the Chairman, Secretary, and members of the LASL Respirator Advisory Committee, and to the ERDA Division of Operational Safety, health 
protection Branch. A copy of this report shall be forwarded iy the section Leader of the LASL RRDS to the ERDA contractor who submitted the airline-type supplied-air suit if the FRDA contractor makes a written request fior a copy of the report.

6.3.2. The LASL Respirator Advisory Committee, after a study of the report mentioned in 6.3.1., shall formulate conclusions and recommendations concerning the adequacy of the performance of the airlinetype supplied-air suit submitted by an ERDA contractor. The Chairman of the LASL Respirator Advisory Comittee shali write a report containing the Committee's conclusions and reconmendations, and shall forward copies of the report to the Section seader of the LASL RRDS and to the ERDA Division of Operational Safety, Health Protection Branch. A copy of this report shall be forwarded by the Chairman of the LASI Respirator Advisory Committee to the ERDA contractor who submitted the device if the ERDA contractor makes a written request for a copy of the report.

6.3.3. The LASL RRDS, after a study of the report mentioned in 6.3 .2$. shall formulate its own conclusions and recommendations concerning the adequacy of the airline-type supplied-air suit submicted by an ERDA contractor and shall write a report containing these conclusions and recommendations. The section Leader of LASL RRDG shall forwara copies of the report to the ERDA Division of Operational Safety, Health Protection Branch, and to the Chairman, Secretary, and members of the LASL Respirator Advisory Committee. A copy of this repart shall be forwarded by the section Leader of the IASI RRDS to the ERDA : ontractor who submitted the device if the ERDA contractor makes a written request for a copy of the report.

6.4. Airline-Type Supplied-Air suit for Use in Tests to Determine Performance Characteristics

6.4.1. The entire airline-type supplied-air suit including the supply air hose and including attachments, accessories, and auxiliary items such as couplings, airflow control valve, air-flow meter, airpressure regulator, air-pressure gage, conmunications equipment, gloves, boots, shce covers, etc. submitted by the ERDA contractor shall be used to determine the performance of the device.

6.4.2. An unused airline-type supplied-air suit provided by the ERDA contractor shall be used in tests to determine the performance of the device.

6.4.3. If the airline-type suppliedair suit is reusable and if the device or a portion of it is laundered, a laundered device or the device with the laundered component submitted by the ERDA contractor shall be used in tests to deterrine the performance of the device. The number of launderings of the device or component sha 11 be recorded and listed in the report containing the results of tests on the device written by the LASL RRDS. Both an urused device and the laundered device for the device containing the laundered component) shall be used in tests involving the use of human test subjects wearing the device in a test atmosphere to determine the degree of protection provided by the device.

6.5. Human Test Subjects

6.5.1. The LASI RRDS shall use three human test subjects in tests requiring the employment of human test subjects to determine the performance of an airline-type supplied-air suit submitted by an ERDA contractor.

6.5.2. Each of the three human test subjects shall be of a different size. The three human test subjects shall have the following heights: (a) 168 to $173 \mathrm{~cm}$

( 5 feet, 6 inches to 5 feet, 8 inches), (b) 180 to $185 \mathrm{~cm}$ ( 5 feet, 11 inches to 6 feet, 1 inch), (c) 191 to $196 \mathrm{~cm}$ (6 feet, 3 inches to 6 feet, 5 inches).

6.5.3. The heights and the weights of each of the three human test subjects shall be determined and recorded. The values for height and weight of each human test subject 
shall be listed in the report containing the resilts of the tests on the airline-type supplied-air suit written by the LASL RRDS. 6.6. Examination

6.6.1. The entire airline-type supplied-air suit including the supply air hose and ircluding attachments, accessories, and auxiliary items submitted by an ERDA contractor shali be examined by the LASL RRDS to determine if it meets tixe requirements set forth in Section 4 of this document. The examination shall include a laundered device or a laundered component cf the device if the device is reusable and the device or a portion of the device is launciereci. If the examination shows that the device does not neet the requirements, it shall not be considered to be acceptable to provide protection of workers against inhalation of harmful atmosphere.

6.6.2. The donning, operation, maintenance, and storage instructions pertaining to the airline-type supplied-air suit submitted by the ERDA contractor shall be eyamined and scudied by the LASL RRDS. If these instructions are considered to be in accurate, confusing, or incomplete, the device shall not be considered to be acceptable to provide protection of workers against inhalation of harmful atmospheres.

6.6.3. If the examination of the airline-type supplied-air suit or the instructions concerning the donning, operation, maintenance, and storage of the device submitted by the ERDA contractor shows that these items do not meet prescribed requirements, no further work on determining the adequacy of the performance of the device shall be carried out by the LASL RRDS.

6.7. Donning and Wearing of Airline-Type Supplied-Air suit by Human Test Subject

6.7.1. Prior to having a human test subject don the airline-type supplied-air suit submitted by an ERDA contractor, a test operator shall attach to the human test subject a suitable harness which contains the appropriate probes and sensing elements for measuring the performance characteristics of the devices.

6.7.2. Prior to donning the airline type supplied-air suit, the human test subject shall don spectacles, hearing protectors, and any other necessary comfort items. 6.7.3. The human test subject shall don and wear the airline-type supplied-air suit in accordance with instructions provided by the ERDA contractor.

6.7.4. The test operator shall examine the covering of the airline-type supplied-air suit worn by the human test subject to observe if the covering contains any punctures, tears, sean separations, loose joints, and ot.uer defects. If any such defects are found, the device shall not be considered to be acceptable to provide protection to workers against inhalation of harmful atmospheres, and no further work on determining the adequacy of the performance of the device shall be carried out by the LASL RRDS. This examination shell also be carried out on a laundered covering if such a covering has been submitted by the ERDA contractor.

6.8. Determination of Ảccuracy of Air-Flow Indicator

6.8.1. The accuracy of the air $-f$ low indicator (direct or indirect reading) of the airline-type supplied-air respirator submitted by an ERDA contractor shall be determined. This shall be accomplished by having a human test subject wear the covering of the device, having the supply air hose connected to a source of respirable air, and by using a suitable calibrated flow-measuring instrument to monitor the rate of flow of respirable air being delivered to the covering of the device. If the ERDA contractor utilizes more than a single length of supply air hose for the device, then the testing of the accuracy of the air-flow indicator of the device shall be carried out for each length of supply air hose. Tests carried out to determine the accuracy of the air-flow indicator of the device shall have each of the three 
human test subjects wear the covering of the device. During each test of the accuracy of the air-flow indicator of the device, the air pressure in the breathing zone of the human test subject wearing the covering of the device shall be measured. This shall be accomplished by means of a probe located inside the head portion of the covering in the breathing zone of the human test subject which is connected to a suitable air-pressure measuring instrument.

6.8.2. During a test of the accuracy of the air-flow indicator of the airlinetype supplied-air suit, the human test subject wearing the covering of the device shall stand still with his arms hanging downward along the sides of his body, and he shall breathe normally.

6.8.3. During a test of the accuracy of the air.-Flow indicator of the airlinetype supplied-air suit, the rate of flow of air to the covering of the device shall be varied from the minimum to the maximum airflow rate flow values specified by the ERDA contructor for a particular iength of supply air hose. The variation of the rate of air flow shall be made in increments of $4.7 ? \times 10^{-4} \mathrm{~m}^{3} / \mathrm{s}(1.0 \mathrm{cfm})$. The accuracy of the air-flow indicator of the device shall be determined for air-flow rate values varying from the minimum to the maximum specified values for air-flow rate increments of $4.72 \times 10^{-4} \mathrm{~m}^{3} / \mathrm{s}(1.0 \mathrm{cfm})$. The air pressure in the breathing zone of the human test subject wearing the covering of the device shall be measured for air-flow rate values varying from the minimum to maximum specified values for air-flow rate increments of $4.72 \times 10^{-4} \mathrm{~m}^{3}$ is $(1.0 \mathrm{cfm})$.

6.8.4. The acceptable accuracy of tine air-flow indicator of the airline-type supplied-air suit shall be plus or minus 10 percent for each air-flow rate value and for each length of supply air hose.

\subsection{Respiratory Protection}

6.9.1. The level of respiratory protection provided by the airline-type supplied-air respirator submitted by an
ERDA contractor shall be determined. In a test carried out to determine the level of respiratory protection provided by the device, a human test subject shall wear the covering of the device, which is connected to a source of respirable air, in an ztmosphere containing a test agent, and the penetration of the test agent irto the interior of the covering of the device in the breatiing zone of the human test subject shall be measured as the subject carries out various exercises. Tests carried out to determine the level of respiratory protection of the device shall have each of the three human test subjects wear the covering of the device.

6.9.2. The test atmosphere to be used to determine the level of respiratory protection provided by the airline-type supplied-air suit shall be a polydisperse dioctyl phthalate (DOP) aerosol. The DOP aerosol particles shall have a mass median aerodynamic aiameter (mmad) of $0.60 \pm 0.12$ $\mu \mathrm{m}$ and a standard deviation (sd) of $2.20 \pm 0.20$. The test atmosphere shall have a DOP aerosol particle concentration of $25 \pm 5 \mathrm{mg} / \mathrm{m}^{3}$.

\subsubsection{A forward light-scattering} photometer and appropriate accessories sha11 be used to detect the DOP aerosol particles in the test atmosphere and inside the covering of the airline-type supplied-air suit in the breathing zone of the human test subject wearing the covering. A suitable recorder, connected to the forward lightscattering photometer, shall be used to record measurements made by the photometer.

\subsubsection{A chamber containing the test} atmosphere shall be used to carry out tests to determine the level of respiratory protection provided by the airline-type supplied-air suit. The chamber shall be of suitable size to permit a test subject wearing the covering of the device to freely carry out the various exercises.

6.9.5. A probe located inside the chamber in the area where a liuman test 
subject wearing the covering of the airlinetype suppliec-air suit will carry out the various exercises and connected by means of tubing to the forward light-scattering photometer shall be used to sample the test atmospherc in order to detect the DoP aerosol particles in the test atmosphere.

6.9.6. A probe located inside the head portion of the covering of the airlinetype supplied-air suit in the breathing zone of the human test subject wearing the covering and which is connected by means of suitable flexible tubing to the forward light-scattering photometer shall be used to sample the air in the humar test subject's breathing zone to detect Dop aerosol particles in his breathing zone.

\subsubsection{The rate of flow of sample} air to the forward light.-scattering photometer either from inside the chamber or from inside the head portion of the covering of the airline-type supplied-air suit shall be $1.33 \times 10^{-4} \mathrm{~m}^{3} / \mathrm{s}(8.01 \mathrm{pm})$.

6.9.8. In carrying out the tests to determine the level of respiratory protection provided by the airline-type suppliedair suit, a suitable length of supply air hose shall be used. A human test subject wearing the covering of the device shall upon entering the test chamber connect the supply air hose to a fitting located inside the chamber which is connected to a source of respirable air. An air-flow control valve and a calibrated air-flow measuring instrument shall be used to control the flow of respirable air to the covering of the device worn by the human test subject inside the chamber and to measure the rate of flow of this air.

6.9.9. The following procedures shall be used to detcrmine the level of respiratory protection provided by the airlinetype supplied-air suit.

6.9.9.1. The human test subject wearing the covering of the device shall enter the test chamber containing the DOP aerosol and shall attach the supply air hose to the fitting inside the chamber which is connected to the source of respirable air. He shall conrest the tubing leading from the probe inside the head portion of the covering of the device to a fitting located inside the chamber which is connected to the forward light-scattering photometer.

\subsubsection{The test operator}

shall adjust the rate of flow of respirable air going to the covering of the device being worn by the human fest subject to the specified minimum value plus $1.33 \times 10^{-4}$ $\mathrm{m}^{3} / \mathrm{s}(3.0 \mathrm{lpm})$ to compensate for the flow of sample air from inside the head portion of the covering of the device to the forward light-scattering photometer. He shall check the oferation of the forward lightscattering photometer and make any necessary adjustments.

6.9.9.3. The human test subject shall carry out the following series of exercises,and the test operator shall insure that the recorder attached to the forward light-scattering photometer records the penetration of the DOP aerosol into the head portion of the covering of the device during each exercise. Each exercise shall be carried out for at least $120 \mathrm{~s}$ (2 $\mathrm{min})$, or until the penetration of DOP aerosol into the head portion of the covering of the device in the breathing zone of the subject becomes steady for at least $60 \mathrm{~s}$ il min).

a. Standing still, arms hanging downward along the sides of body, nurmal broathing.

b. Bending forward and touching toes repeatedly.

c. Running in place.

d. Raising arms above head and looking upward repeatedly.

e. Bending knees and squatting repeatedly.

f. Crawling on hands and knees.

g. Standing with arms folded in front of chest and twisting torso from side to side repeatedly.

h. Standing still, arms hanging downward along sides of body, normal breathing. 
6.9.9.4. Before carrying out each of the exercises listed in $c, d, e, f$, and $g$ of 6.9.9.3., the human test subject shall. stand still with his arms hanging downward along the sides of his body and breatlis normaily for 120 to $180 \mathrm{~s}(2$ to 3 $\mathrm{min}$ ) to purge the air inside the covering of the device in case the previous exercise resulted in a high penetration of DOP aerosol into the interior of the covering.

\subsubsection{If the penetration}

of Dop aerosol into the interior of the cuvering of the device in the breathing zone of the human test subject exceeds 20 , the test shall be terminated to prevent undue exposure of the subject to the DOP aerosol.

6.9.9.6. After the exercise

described in $h$ of 6.9 .9 .3 . has been carried out by the human test subject, the test operatcr shall. stop the flow of respirable air to the covering of the device worn by the subject, and the subject shall continue to stand still with his arms hanging downward along his sides and breathe normally. The test operator shall observe the increase in penetration of the DOP aerosol into the covering of the device in the breathing zone of the human test subject, and he shall record the time periods that extend from the instant that the flow of air was terminated to the moments that the DOP aerosol penetration reaches values of $0.5 \%, 0.18$, and 18 . The test operator then shall restore the flow of respirable air to the covering of the device worn by the human test subject, and the subject shall remain standing still with his arms hanging downward along his sides and breathe normally until the DOP aerosol penetration returns to approximately the value occurring before the flow of respirable air to the covering of the device was terminated.

\subsubsection{The DOP aerosol} penetration values in the breathing zone of che human test subject wearing the covering of the device may oscillate during a given exercise carried out by the subject due to the breathing of the subject. Deak DOP aerosol penetrations occur during inhalation.

\subsubsection{Determine the aver-} age of the peak DOP aerosol penetration values which occurred during each of the exercises carried out by the human test subject listed in 6.9.8.3. and record these average peak DOP aerosol penetration values.

\subsubsection{Caiculate the aver-}

age of the average peak DOP aerosol penetration values determined in 6.9.9.8. and record this value which represents the average neak DOP aerosol penetration for all exercises carried out by the human test subject.

$$
\text { 6.9.9.10. Repeat 6.9.9.3. }
$$

through 6.9.9.9. For increasing increments of rate of air flow into the covering of the device worn by the human test subject of $4.72 \times 10^{-4} \mathrm{~m}^{3} / \mathrm{s}(1.0 \mathrm{cfm})$ up to the maximum airflow rate specified by the ERDA contractor plus $1.33 \times 10^{-4} \mathrm{~m}^{3} / \mathrm{s}(8.03)$. to compensate for the flow of sample air from inside the head portion of the covering of the device to the forward light-scattering photometer.

$$
\text { 6.9.9.11. Repeat 6.9.9.1. }
$$

through 6.9.9.10. for each of the other two human test subjects.

$$
\text { 6.9.9.12. If the airline-type }
$$

supplied-air suit is reusable and if the device or a por.: an of it is laundered, a laundered device or the device with the laundered component submitted by the ERDA contractor shall also be tested in accordance with 6.9.9.1. through 6.9.9.11.

6.9.10. The airline-type suppliedair suit shall be acceptable in regard to providing respiratory protection if the average peak DOP aerosol penetrations into the head portion of the covering of the device in the breathing zone of the human test subjects who wore the covering does not exceed $0.01 \%$ for all exercises for all values of the rate of air flow into the covering of the device ranging from the minimum value to the maximum value specified by the ERDA contractor. 
6.10. Crush Fesistance of Supply Air Hose

6.10.1. The crush resistance of the

supply air hose of the airline-type suppliedair suit submitted by an ERDA contractor shall be determined. In a test carried out to determine the crush resistance of the supply air hose, the reduction in the flow of air through the hose when a crushing force is applied to the hose is measured. 6.10.2. A suitable length of the supply air hose shall be connected to a source of compressed air and a calibrated air-flow measuring instrument shall be used to monitor the rate of flow of air through the hose.

6.10.3. The rate of flow of air through the supply air hose shall be adjusted to the minimum value specified by the ERDA contractor.

6.10.4. The supply air hose shall rest on a horizontal plane surface. A crushing force of $113.5 \mathrm{~kg}(250 \mathrm{lb})$ shall be applied to the hose along $7.6 \mathrm{~cm}$ ( $3 \mathrm{in}$ ) of its length for $300 \mathrm{~s}(5 \mathrm{~min})$.

6.10.5. The rate of flow of air through the supply air hose curing the application of the crushing force shall be observed. The lowest value of the rate of. flow of air through the hose shall be recorded. The maximum decrease in the rate of air flow through the hose shall be calculated and recorded.

6.10.6. After removal of the crushing force from the supply air hose, the condition of the section of the hose where the crushing force had been applied shall be examined, and a record shall be made of any permanent deformation of the hose.

6.10.7. The supply air hose shall

be acceptable in regard to crush resistance if the lowest rate of flow of air through the hose durirg the application of the crushing force is not less than $90 \%$ of the original rate of flow of air through the hose, and if permanent deformation of the hose does not occur due to the application of the crushing force.
6.11. Norkinkability of Supply Air Hose

6.11.1. The nonkinkability of the supply air hose of the airline-type suppliedair suit submitted by an ERDA contractor shall be letermined. In a test caritied out to determine the nonkinkability of the supply air hose, the reduction in the flow of air through the hose when a single-coil loop of the hose is straightened out is measured.

6.11.2. A suitable length of the supply air hose shall be connected to a source of compressed air, and a calibrated air-flow measuring instrument shall be used to monitor the rate of flow of air through the hose.

6.11.3. The rate of flow of air through the supply air hose shall be adjusted to the minimum value specified by the ERDA contractor.

6.11.4. A $1.83 \mathrm{~m}$ (6 ft) diameter single-coil loop of the supply air hose shall be formed with the loop on a horizontal plane surface.

\subsubsection{At a distance of $0.91 \mathrm{~m}$}

(3 ft) from the single-coil loop, one of the sections of the supply air hose which extends from the loop and which leads to the source of compressed air is securely fastened to the horizontal plane surface.

6.11.6. The portion of the supply air hose which extends from the single-coil loop, and which is not fastened to the horizontal plane surface, is slowly pulled tangentially to the horizontal plane surface until the loop unfolds and the hose straightens out.

6.11.7. The rate of flow of air through the supply air hose shall be observed during the time that the single-coil loop of the hose is unfolded and the hose is straightened out. The lowest value of the rate of flow of air through the hose during the hose-straightening process shall be recorded. The maximum decrease in the rate of air flow through the hose as a percentage of the original flow rate shall be calculated and recorded. 
6.11.8. The way in which the singlecoil loop of the air hose unfolds shall be observed, anã a record shall be made of any localized kinking of the hose.

6.11.9. The supply air hose shall be acceptable in regard to nonkinkability if, during the process of unfolding the single-coil loop of hose, the lowest rate of flow of air through the hose is not less than 908 of the original rate of flow of air through the hose, and if localized kinking of the hose does not occur.

6.12. Strength of Supply Air Hose and Couplings

6.12.1. The strength of the supply air hose and couplings of the airline-type supplied-air suit submitted by an ERDA contractor shall be determined by two tests. Suitable lengths of the supply air hose containing the couplings shall be used in the tests. If more than one type of coupling is used in the device, then a length of supply air hose with each type of coupling shall be tested.

6.12.2. The supply air hose and coupling shall be connected to a source of compressed air, and a calibrated air-flow measuring instrument shall be used to monitor the rate of flow of air through the hose and coupling.

6.12.3. The rate of flow of air through the supply air hose and coupling shall be adjusted to the minimum value specified by the ERDA contractor.

6.12 .4 . A steady pull of $113.5 \mathrm{~kg}$ (250 1b) for $300 \mathrm{~s}$ ( $5 \mathrm{~min}$ ) shall be made on the supply air hose and coupling.

6.12.5. The supply air hose and coupling shall be observed during the steady pull. Any breaking of the hose, separation of the hose and coupling, and separation of components of the coupling shall be recorded.

6.12.6. The rate of flow of air through the supply air hose and coupling during the steady pull shall be observed. The lowest value of the rate of flow of air through the hose and coupling shall be recorded. The maximum decrease in the rate of air flow through the hose and coupling as a percentage of the original air-flow rate shall be calculated and recorded.

6.12 .7 . A rapid pull of $113.5 \mathrm{~kg}$ (250 $\mathrm{lb}$ ) of $0.5 \mathrm{~s}$ duration or less shall be made on the supply air hose and coupling. A total of three of these rapid pulls shall be carried out.

6.12.8. The supply air hose and coupling shall be observed after each of the three rapid pulls. Any breaking of the hose, separation of the hose and coupling, and separation of components of the coupling shall be recorded.

6.12.9. The rate of flow of air through the supply air hose and coupling during each of the three rapid pulls shall be observed. The lowest value of the rate of flow of air through the hose and coupling during each rapid pull shall be recorded. The maximum decrease in the rate of air flow through the hose and coupling as a percentage of the original air-flow rate shall be calculated and recorded.

6.12.10. The procedures given in

6.12.2. through 5.12.9. shall be carried out on the supply air hose and each type of coupling used.

6.12.11. The strength of the supply air hose and couplings of the airline-type supplied-air suit shall be acceptable if, during the prescribed tests, breaking of the hose, separation of the hose and couplings, and separation of components of couplings does not occur, and the lowest rate of flow of air through the hose and couplings is not less than 908 of the original rate of flow of air through the hose and couplings.

6.13. Strength of Connection of Supply Air Hose to Covering

6.13.1. The strength of the connection of the supply air hose to the covering of the airline-type supplied-air suit submitted by an ERDA contractor shall be determined by means of a test involving a measure of the level of respiratory protsction provided by the device when the connection of 
the supply air hose to the covering is subjected to a separating force. In the test, a human test subject shall wear the covering of the device, which is connected by means of the supply air hose tc a source of respirable air, in an atmosphere containing a test agent, and the penetration of the test agent into the interior of the covering of the device in the breathing zone of the human test subject shall be measured as the subject carries out an exercise aimed at testing the strength of the connection of the supply air hose to the covering.

6.13.2. The test atmosphere to be used in the test to determine the strength of the connection of the supply air hose to the covering of the device shall be a polydisperse DOP aerosol. A description of the polydisperse DOP aerosol, the instrumentation, and methods which shall be used to measure the penetration of the aerosol into the interior of the covering of the device in the breathing zone of the human test subject, is given in 6.9.2. throuat 6.9.7.

6.13.3. In carryiny out the test to determine the strengt! of the connection of the supply air hose to the covering of the device, a suitable length of supply air hose shall be used, and any of the three human test subjects shall be used. The length of the supply air hose shall be short enough to permit the carrying out of the procedure described in 6.13.7.

6.13.4. The human test subject.wearing the covering of the device upon entering the test chamber, shall connect the supply ait hose to a fitting located inside the chamter which is connected to a source of respirable air. An air-flcw conerol valve and a calibrated air-flow measuring instrument shall be used to control the flow of respirable air to the cotering of the deyice worn by the human cest subject instue tho chamber to measure the low of this air.

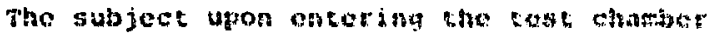

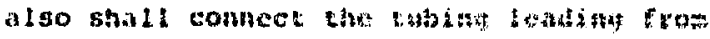

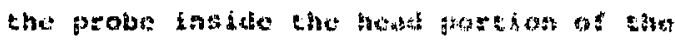

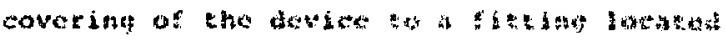

inside the chamber which is connected to the forward light-scattering photometer.

6.13.5. The test operator shall adjust the ratu of flow of respirable air going to the covering of the device being worn by the human test subject to the minimum air-flow rate value specified by the ERDA contraćtor plus $1.33 \times 10^{-4} \mathrm{~m}^{3} / \mathrm{s}$ (8.0 $\mathrm{lpm}$ ) to compensate for the flow of sample air from inside the head portion of the covering of the device to the forward light-scattering photometer. He shall check the operation of the forward light-scattering photometer and make any necessary adjustments.

6.13.6. The human test subject shall stand still with his arms hanging downward along the sides of his body, and he shall breathe normally for at least $120 \mathrm{~s}$ (2 min) or until the penetration of DOP aerosol into the head portion of the covering of the device in the breathing zone of the subject becomes steady for at least $60 \mathrm{~s}$ (1 $\mathrm{min}$ ).

6.13.7. The human test subject shall walk at a normal pace away from the point where the supply air hose of the device is connected to the fitting located inside the chamber. He shall continue to walk until stopped by the limited length of the supply air hose. The subject shall stand still while keeping a steady tension on the taut supply air hose for at least $120 \mathrm{~s}(2 \mathrm{~min})$ or until the penetration of DoP aerosol into the head portion of the covering of the device in the breathing zone of the subject becomes steady for at least $60 \mathrm{~s}(1 \mathrm{~min})$.

6.13.8. The Dor aerosol penetration

viwes in the broathing and of the human test subject wearing the covering of the device may oseillate during the time that the subject keopo at teaty cension on the

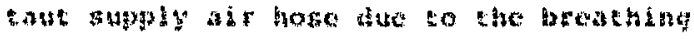

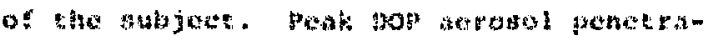

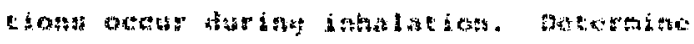

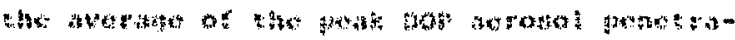
4.

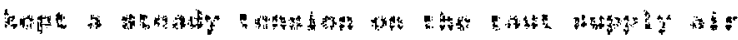

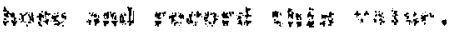


6.13.9. The strength of the connection of the supply air hose to the covering of the airline-type supplied-air suit shall be acceptable if the average peak penetration of the DOP aerosol penetration into the covering of the device in the breathing zone of the human test subject which occurred while the subject maintained a steady tension on the taut supply air hose does not exceed 0.018 .

6.14. Noise

6.14.1 The level of noise generated by the flow of air through an airline-type supplied-air suit submitted by an ERDA contractor shall be determined. In tests carried out to determine the level of noise generated by the flow of air through the device, a human test subject shall wear the covering of the device, which is connected by means of a supply air hose to a source of respirable air, and the level of the noise inside the head portion of the covering at the ears of the subject shall be measured.

6.14.2. In conducting tests to determine the level of noise generated by the flow of air through the device, a suitable lengich of supply air hose shall be used, and any of the three human test subjects shall he used.

6.14.3. The special equipment used to carry out the noise level tests shall include an omnidirectional microphone and extension cord, a sound level meter, a sound level calibrator, and a harness to hold the microphone at the opening of the ears of the human test subject.

6.14.4. Prior to carrying out the noise level tests, the noise level measuring s'stem consisting of the microphone mounted in the harness and connected by means of the extension cord to the sound level meter, shall be calibrated for the "A" scale on the octave band sound analyzer with the aid of the sound level calibrator.

6.14.5. The test operator shall ottach the harness containing the mounted microphone to the human test subject, and he shall insure that the microphone is located at the opening of the subject's right ear. The subject shall don the covering of the airline-type supplied-air suit in accordance with instructions provided by the ERDA contractor.

6.14.6. The test operator shall make a measurement of the background noise level on the "A" scale of the sound level meter. During this measurement, there shall not be any flow of respirable air to the covering of the device, the human test subject shall stand still with his arms hanging downward along his sides and he shall hold his breath. The background noise level shall be recorded. Tests to measure the level of noise generated by the flow of air through the covering of the device shall not be carried out if the background noise level exceeds 74 dBA.

6.14.7. The test operator shall connect the supply air hose to a source of respirable air. An air-flow control valve and a calibrated air-flow measuring instrument shall be used to control and measure the rate of flow of respirable air to the covering of the device worn by the human test subject.

6.14.8. During tests conducted to determine the level of noise generated by the flow of air through the device, the human test subject, wearing the covering of the device, shall stand still with his arms hanging downward along his sides, and he shall breathe normally.

6.14.9. The test operator shall adjust the rate of flow of respirable air going to the covering of the device being worn by the human test subject to the minimum airflow rate value specified by the ERDA contractor. He shall observe the measurement of the noise level as given by the " $A$ " scale of the sound level meter, and he shall record this measurement.

6.14.10. The test operatcr shall increase the rate of flow of respi rable air going to the covering of the device being worn by the human test subject in increments of $4.72 \times 10^{-4} \mathrm{~m}^{3} / \mathrm{s}(1.0 \mathrm{cfm})$ up to the 
maximum air-flow rate specified by the ERDA contractor. The test operator shall observe the measurement of the noise level as given by the "A" scale of the sound level meter for each air flow rate, and he shall record each measurement.

6.14.11. The human test subject shall remove tre covering of the device, and the test jerator shall change the attachment of the harness containing the microphone so that the microphone is locater at the opening of the subject's left ear. The subject shall don the covering of the device. The procedures given in 6.14.6. through 6.14 .10 shall be repeated.

6.14.12. The level of noise generated by the flow of air through an airlinetype supplied-air suit shall be acceptable if the highest noise level measured does not exceed $80 \mathrm{dBA}$. 